LA W RENCE LIVERM ORE NATIONAL LABORATORY
Foreign Travel Trip Report for LLNL travel with DOE FES funding,May 19th-30th, 2012

I. Joseph

July 6,2012 
This document was prepared as an account of work sponsored by an agency of the United States government. Neither the United States government nor Lawrence Livermore National Security, LLC, nor any of their employees makes any warranty, expressed or implied, or assumes any legal liability or responsibility for the accuracy, completeness, or usefulness of any information, apparatus, product, or process disclosed, or represents that its use would not infringe privately owned rights. Reference herein to any specific commercial product, process, or service by trade name, trademark, manufacturer, or otherwise does not necessarily constitute or imply its endorsement, recommendation, or favoring by the United States government or Lawrence Livermore National Security, LLC. The views and opinions of authors expressed herein do not necessarily state or reflect those of the United States government or Lawrence Livermore National Security, LLC, and shall not be used for advertising or product endorsement purposes.

This work performed under the auspices of the U.S. Department of Energy by Lawrence Livermore National Laboratory under Contract DE-AC52-07NA27344. 


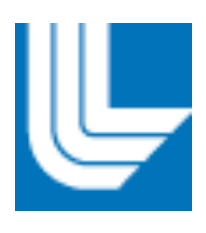

LLNL-IM-XXXXXX

\section{Foreign Travel Trip Report for LLNL travel with DOE FES funding*}

Name, Position, Organization, Phone No:

Ilon Joseph, Physicist, Fusion Energy Sciences Program, Physical \& Life Sciences Division, LLNL, 925-422-3737

Date of Trip Report: $\quad$ June $20^{\text {th }}, 2012$

Dates of Travel: $\quad$ May $19^{\text {th }}-30^{\text {th }}, 2012$

DOE Trip Number(s): $\quad$ FTS ID: 40971-01; DOE ID: 1211985

DOE/HQ FES Sponsor: $\quad$ OFES

Destinations (Installation, City and Country):

1. $20^{\text {th }}$ International Conference on Plasma Surface Interactions (PSI) in Fusion Devices, Aachen, Germany

2. Centre de Recherches en Physique des Plasmas (CRPP), Ecole Polytechnique Federale de Lausanne (EPFL), Lausanne, Switzerland

\section{Statement of Trip Purpose:}

Attend the 20th biannual International Conference on Plasma Surface Interactions in order to disseminate results from LDRD project 11-ERD-058 on controlling ELM transport in fusion plasmas and to participate in and learn of the most recent results in plasma surface-interactions. Visit the Centre de Recherches en Physique des Plasmas (CRPP) to disseminate results on ELM control and collaborate with the TCV and TORPEX groups at the CRPP.

\section{List of Persons Contacted:}

1. PSI: many conference attendees, including T. Eich, H. Frerichs, M. Groth, G. Huijsmanns, B. LaBombard, A. Kukushkin, S. Krasheninikov, R. Maingi, V. Rozhanksy, D. Rudakov, O. Schmitz, M. Wischmeier. A complete list of speakers and presenters can be found at https://www.congressa.de/PSI2012/index.php?article_id=65

2. CRPP, EPFL: I. Furno, H. Reimerdes, P. Ricci

\section{List of Facilities Visited:}

1. Eurogress Conference Center, Aachen, Germany

2. Centre de Recherches en Physique des Plasmas (CRPP), Ecole Polytechnique Federale de Lausanne (EPFL), EPFL 


\section{Abstract (i.e. major highlights, benefits of the travel, results of meetings):}

I attended the $20^{\text {th }}$ biannual International Conference on Plasma Surface Interaction (PSI) in Fusion Devices in Aachen, Germany, hosted this year by the Forschungszentrum Julich (FZJ) research center. The PSI conference is one of the main international forums for the presentation and discussion of results on plasma surface interactions and edge plasma physics relevant to magnetic confinement fusion devices. I disseminated the recent results of FESP/LLNL tokamak research by presenting three posters on: (i) understanding reconnection and controlling edge localized modes (ELMs) using the BOUT++ code, (ii) simulation of resistive ballooning mode turbulence, and (iii) innovative design of Snowflake divertors. I learned of many new and recent results from international tokamak facilities and had the opportunity for discussion of these topics with other scientists at the poster sessions, conference lunches/receptions, etc. Some of the major highlights of the PSI conference topics were:

1. Review of the progress in using metallic tungsten and beryllium (ITER-like) walls at international tokamak facilities: JET (Culham, UK), TEXTOR (FZJ, Germany) and Alcator CMOD (MIT, USA). Results included: effect of small and large-area melting on plasma impurity content and recovery, expected reduction in retention of hydrogenic species, increased heat load during disruptions and need for mitigation with massive gas injection.

2. A review of ELM control in general (T. Evans, GA) and recent results of ELM control using $n=2$ external magnetic perturbations on ASDEX-Upgrade (MPI-Garching, Germany).

3. General agreement among the international tokamak database that, along the outer midplane of a low collisionality tokamak, the SOL power width in current experiments varies inversely with respect to plasma current (Ip), roughly as $1 / \mathrm{Ip}$, with little dependence on other plasma parameters. This would imply roughly a factor of $1 / 4$ of the width that was assumed for the design of the ITER tokamak. The first studies of the implications for ITER (A. Kukushkin, ITER) have shown a great reduction in operational parameter space that, at present, can only be lifted by increasing target plate heat flux limits.

During my visit to the CRPP at the EPFL, I delivered an invited talk in order to disseminate new results of the recent publication [1] on using non-axisymmetric perturbations of the SOL to control the edge plasma. I was given a tour of both the TCV tokamak and the TORPEX simple magnetized plasma device/divertor simulator. TORPEX is an excellent laboratory for exploring the physics of simple magnetized plasmas that are relevant to the scrape-off layer of a tokamak. Properly designed experiments on TORPEX can potentially be used to test the theory of controlling the edge plasma using non-axisymmetric potentials and currents in the SOL developed by LLNL described in [1].

[1] I. Joseph, et al, Phys. Plasmas 19, 056124 (2012).

\section{Statement of Activities:}

1. Attended the 20th International Conference on Plasma Surface Interactions 2012 at the Eurogress Conference Center in Aachen, Germany. Presented a contributed poster: I. Joseph, et al., "Flute-reduced drift-MHD model for tokamak edge plasma response using the BOUT++ code" on May $21^{\text {st }}, 2012$. In addition, presented two other contributed posters on May $21^{\text {st }}, 2012$ by FESP/LLNL scientists: (i) B. I. Cohen, et al., "BOUT Simulations of Drift Resistive Ballooning Turbulence in the DIII-D Tokamak" and (ii) T. D. Rognlien, et al., "Comparison of ELM heat loads in snowflake and standard divertors." 
2. Presented an invited talk, entitled "Using non-axisymmetric scrape-off-layer perturbations to control the tokamak edge plasma," at the Centre de Recherches en Physique des Plasmas on May $29^{\text {th }}, 2012$. Toured the experimental facilities of (i) the Tokamak a Configuration Variable (TCV tokamak) and (ii) the TORPEX simple toroidal plasma device. Spoke with Prof. P. Ricci about possible future collaboration between LLNL and CRPP on the topic of boundary and scrape-off layer (SOL) plasma turbulence simulation. Spoke with senior scientist I. Furno about possible experiments that can be performed on TORPEX to test the theory of the generation of SOL currents and perturbations to the SOL plasma.

\section{Recommendations about Follow Up Activities:}

Plasma surface interaction issues are of critical importance to the success of future magnetic confinement fusion experiments and reactors, including ITER. It is important for the US DOE to keep abreast of and play a role in the solution of these issues by participating in this international research topic and in future PSI conferences.

The TORPEX group has invited FESP to collaborate on the advancement of the understanding of boundary plasma turbulence in simple magnetized plasma. Additional contact with I. Furno is planned. This will complement the ongoing collaboration between the TCV tokamak group at CRPP/EPFL and FESP/LLNL on innovative divertor design.

\section{Description of Any Security Related Concern Which Occurred During Trip: None}

* Travel approved by Defense Programs (DP) and Nonproliferation (NN) no longer requires a Trip Report. However, Actual Cost Reports and trip summary must still be submitted through FTS within 20 days of the return date. 